\title{
Retaining Talented Salespeople
}

\author{
Steven Lu • Andre Bonfrer • Ranjit Voola
}

Published online: 2 April 2015

(C) Springer Science+Business Media New York 2015

\begin{abstract}
For any marketing organization that relies on personal selling, it is vital to attract and retain successful salespeople who fit well with the organization. In this paper, we examine how salespeople learn about their fit with the organization and about their future performance and how they use this to make the decision to stay or leave. We depart from the extant sales management literature on retention/turnover in that we model individual sales employees' stay/leave decisions using a structural model that accommodates forward looking behaviour. In our application, the dynamic model explains turnover better than a model that does not consider forward looking behaviour. Our approach also immediately yields several insights about the roles of person-organization fit and sales performance satisfaction in sales force turnover. Overall, and accounting for personorganization fit, we find that good performance encourages
\end{abstract}

Electronic supplementary material The online version of this article (doi:10.1007/s40547-015-0045-0) contains supplementary material, which is available to authorized users.

\section{S. $\mathrm{Lu}$}

University of Sydney Business School, Rm 503, The University of Sydney, Sydney, NSW 2006, Australia

e-mail: steven.lu@sydney.edu.au

\section{A. Bonfrer $(\square)$}

Research School of Management, The Australian National University, LF Crisp Building 26C, Canberra, Australia e-mail: andre.bonfrer@anu.edu.au
A. Bonfrer
College of Business and Economics, Canberra, Australia
R. Voola
The University of Sydney, Sydney, NSW 2006, Australia
e-mail: ranjit.voola@sydney.edu.au

the salesperson to stay longer with the selling organization. Most importantly, the relative importance of personorganization fit and salesperson performance in determining turnover varies over time. In particular, person-organization fit plays a bigger role at the beginning of a salesperson's tenure, whereas satisfaction associated with selling performance plays a larger relative role at later stages.

Keywords Salesforce turnover · Salesperson performance $\cdot$ Person-organisation fit $\cdot$ Dynamic choice model

\section{Introduction}

A major challenge in sales force management is how to grow and maintain a productive sales force, a task that involves balancing the benefits and costs of retaining successful salespeople. Salespeople assess their long-term utility of staying with the firm based on a combination of performance and how well they fit with the organization. Organization behaviour theorists extol the importance of person-organization fit, defined as "how compatible employees are with their organization" [39]. They also consider the benefit of keeping high performance employees (e.g. Baron et al. [5]). Employees' close fit with the organization has been shown to improve organization commitment [41], lowering the propensity for employees to leave the firm. Similarly, keeping high performance salespeople is believed to be beneficial, because of their direct impact on profitability, and because of the institutional/tacit knowledge they possess about customers and markets. In conjunction, the message to sales managers is that to maximize sales force productivity it is best, and most efficient, to keep high performance salespeople who fit well with 
the organization. It is therefore important to consider how salespeople develop their expectations about fit and future performance and how they use this to make their decisions to stay or leave the organization. Crucially, this assessment is based on an assessment of their future utility to stay with the organization.

In this study, we consider the dynamic joint impact of person-organization fit and salesperson performance, on voluntary turnover. Voluntary turnover relates to the sales person's decision to leave their existing employer $[6,50]$. This is distinct from involuntary turnover (from the perspective of a salesperson) which can occur because the salesperson can no longer function effectively in that position. We take a more causal view of the problem, by allowing person-organization fit and performance to evolve as state variables, from the time a salesperson starts his or her job. The business rationale for studying both antecedents in the same model is that there are a number of benefits to keeping salespeople who fit well with the organization (e.g. see a meta-analysis of Kristof-Brown et al. [41]), and that it is better for business development to keep high performing salespeople. However, both of these evolve over time, as salespeople learn from their on the job activities as to how they will fit and perform. Thus, a careful examination of these two components needs to be done at an individual salesperson level and needs to study the trajectories of learning as they stay with the organization. Past research on salesforce turnover considers these two aspects usually cross sectionally (with the exception of e.g. Bridges et al. [10]) and separately. As a summary of our research problem, what appears to be neglected in past work on salesforce turnover is a joint consideration of the effect on turnover of sales employees' expectation about person-organization fit and selling performance. Most previous studies also do not consider explicitly how salespeople learn over time from activities on their job.

We examine a dynamic choice problem wherein salespeople evaluate, each period, whether there is a net benefit to them staying with the organization. In our longitudinal study, salespeople are observed over time from their date of recruitment, up to the point where they leave the firm. Sales employees learn (over time) about their selling performance from observed success rates, and about their fit with the organization from the activities that surround handling sales cases. Based on what salespeople learn, they construct overall expectations about the benefits of staying with the organization versus leaving. Our structural model is the first attempt to capture these dynamics and the learning underlying the turnover decision at an individual salesperson level. The benefit of using a structural approach lies in the ability to examine and extrapolate the trajectories of individual sales persons' jobs with the organization.
Thus, our goal in this study is to incorporate a two-pronged learning mechanism into a structural form to assess antecedents of sales force turnover, identified through matching forward looking behaviour with stayleave decisions. Based on Erdem and Keane [19]'s Bayesian sequential learning model and dynamic model to study consumer decisions, we develop an analagous dynamic salesperson learning model to estimate sales employee's decisions to stay or leave the organization. We add to the learning mechanism suggested by Erdem and Keane [19], a way to incorporate vicarious learning, and since we observe objective performance, we are able to better identify the latent person organizational fit construct over time.

In this dynamic setting, newly recruited salespeople use prior information to examine both their likely fit and their expected performance with the organization. In our model, the prior belief about performance is identified from the distribution of performance across the incumbent salesforce. The prior distribution of any new salesperson's organization fit is estimated in the model.

We use this model to provide insights into how both future selling performance and person organization coevolve in a salesperson's consideration of whether to stay or leave the selling organization. Salespeople are also more likely to stay if they perform better than their personal expectations on future performance. This finding on performance holds regardless of whether learning about fit is explicitly included or not. We further present evidence in support of the theory that salespeople who develop strong fit with the organization are more likely to stay. We also find that the relative contribution of fit and performance to the utility of staying with the sales team is non-monotonic over the tenure of the newly salesperson. The relative importance of person-organization fit starts reasonably high, increases over around a 3-4 month "honeymoon" period to a maximum at around 5-6 months, and then begins to decline.

Finally, we examine the effect of the organization in raising the prior (the mean) on new sales employees' organization fit. This can be achieved, for example, using simple persuasion by sales managers that they would fit well with the organization. We find that their prior belief about person-organization fit is quickly (in our context, within 1 to 2 months) updated with on the job sales activities. Thus, a sales managers' strategy to set inflated priors on organization fit would be ineffective.

We highlight several important contributions of this study. First, we contribute to the sales force literature by providing a better understanding for how salespeople make forward looking decisions based on a pattern of activities and learning from the date they are employed. Instead of examining cross-sectional variation for reasons 
that salespeople leave, we observe each salesperson from the time they started and consider how they make stay/leave decisions on a periodic basis.

Second, this is the first time that both organizational fit and performance-based expectations are incorporated in understanding the reasons why salespeople leave the organization. While person-organization fit is studied extensively in the management literature, and in the context of salesforce citizenship behaviour (e.g. Netemeyer et al. [59]), it has not been considered very much in understanding how it explains the way salespeople stay with the organization. Moreover, understanding how performance explains salespeople's decision to leave is a topic of considerable interest, because of the direct impact of individual salesperson expected performance on the aggregate performance of the selling organization.

Third, we explicitly model learning by salespeople about performance and about person organization fit. Learning about performance has been linked to favorable outcomes as it leads to more confidence [26] and greater skill [43]. Understanding how salespeople learn about their fit with the organization is critical because individual learning lays the foundation for organizational learning [4] and influences perceptions, behaviour and attitudes within the salesforce. Learning about person-organization fit is also important because it reduces role ambiguity by providing clarity about the expectations of the job role [43] and increases satisfaction as it allows salespeople to understand how their job fits with a firm's overall mission and has been linked to lower employee turnover [29]. Individual learning by salespeople has been highlighted as an important topic for further study in sales research [16]. Through the dynamic modelling of the stay/leave decision, we also contribute to the theoretical understanding of sales force turnover, by generating insights into the process of learning about fit, future performance and their relative impact on sales force turnover.

Fourth, we also can cast our contributions in the context of the management literature. Our model recognizes the sequential nature of choices [45], and how salespeople will use forward looking behaviour to make their decisions to stay or leave. Lee and Mitchell [45]'s unfolding model of employee turnover, for example, proposes that the turnover decision may follow one of five paths. An important path is their "path 1", which is some concurrent environmental event that can cause the sales person to leave. In our model, this environmental event is explicitly weighed up against the utility of staying with the organization, the latter being determined by a discounted utility function containing trajectories of future satisfaction and organization fit.

The importance of this topic is also underscored by the importance of the sales function in many organizations.
The contemporary sales function has a greater strategic role within the organization [64] with clear implications for business strategy [35, 61]. Salespeople are the interface between the organization and its customers [15, 23] and play an important role in identifying opportunities for the firm [20]. Furthermore, sales force management is widely recognized as the most expensive aspect of marketing for many organizations [6, 25]. For example, the average cost of a personal sales call ranges from $\$ 200$ to $\$ 300$, whilst the cost of closing a sales call can range from $\$ 800$ to $\$ 1,200$, and U.S. firms spend over a trillion dollars annually in sales force related expenses [38]. Salesforce turnover is also typically higher than in other occupations [9], so the costs of replacement of sales people is magnified by this high turnover. It is therefore critical to find ways to manage turnover. Approaches which consider both the performance, and fit with the organization, while simultaneously recognising that salespeople are forward looking, are needed understanding how to manage sales employee turnover. Our study is a first step in this direction, and we encourage further research that takes this type of approach. This work will inspire a better understanding of the process by which salespeople make their stay/leave decisions and can provide guidance to sales management to find ways to proactively mitigate future turnover rates.

The remainder of the paper is structured as follows. In the next section, we discuss our model, linking it to a conceptual framework that integrates on the job (sales) activities with learning behaviour. We develop a dynamic forward looking model of the utility for staying with the organization and discuss how person organization fit and expected performance are built in as state variables that salespeople learn about from the time they start with the organization. We then outline our application (a single selling organization tracking each salesperson since the date they started) and present our results. Our last two sections highlights some important implications based on our results, and on the basis of our conceptual model and results, we discuss opportunities for further research in this area.

\section{Model Development}

\subsection{Key Constructs and Salesforce Turnover}

Fundamental to our model is the assumption that an individual salesperson makes the decision to stay with the organization based on an assessment of the future utility of doing so, relative to that of leaving to pursue their career elsewhere. Our model explicitly considers how salespeople's expectations about their utilities evolve over time (see Bridges et al. [10], Bentein et al. [8]), as a function of their 
observations from on the job activities and selling success rates (i.e. how they use updated information).

From the past literature on both sales force retention and organizational behaviour, we draw out two important and distinct constructs from which salespeople derive utility. The first is job performance, in our application measured by their expected success rate (percent of leads successfully closed), from which salespeople derive utility primarily from the financial rewards, although this could also generate utility via job performance satisfaction (the utility of a "job well done"). The second component is person organization fit, which is a latent measure that represents the compatibility of employees and the organization, based on similar fundamental characteristics such as mutual need fulfillment, value congruence, personality similarity between individuals and other members of the organization, and shared individual and organizational goals [40, 59]. Personorganization fit is likely to be unobserved except to the salesperson (although it could be elicited via surveys), while success rate is observed by everyone.

\subsubsection{Expected Performance and Turnover}

We are guided by a substantial literature in salesforce management that has studied the impact of performance on turnover. A central issue is whether high performance salespeople are more or less likely to stay. While successful salespeople have more outside opportunities available, they are also more likely to be well rewarded for their performance in their current role. The past theoretical literature (e.g. McNeilly and Goldsmith [53], McEvoy and Cascio [52], Williams and Livingstone [67], Bridges et al. [10]) provides conflicting and ambiguous conclusions to the performance-voluntary turnover relationship. Some researchers [34] and [22, 27, 49] have found that performance exerts a significant negative effect on voluntary turnover. On the other hand, empirical evidence shows that performance does not influence attrition [24]. Further complicating the relationship, higher performing sales people were more likely to voluntarily leave their job, than sales people who are not performing well [3], whilst others have found the opposite [51]. A curvilinear relationship between selling performance and turnover has also been suggested where the low performers left because of decreasing job security and high performers left the organization due to better external opportunities [31].

\subsubsection{Person-organization Fit}

Drawing from the organization behaviour literature, a second key construct that must be considered as an antecedent for sales force turnover, is the fit between the sales person and the organization. Person-organization fit captures a holistic compatibility between the salesperson and the organization [39, 41]. Person organization fit has been found to have a positive association with job satisfaction $[11,14,59]$ and organizational commitment [41]. In their meta-analysis, Kristof-Brown et al. [41] find that person-organization fit has a strong correlation with job satisfaction (.44) and organizational commitment (.51) and negatively related to intention to quit $(-.35)$. Organizational commitment refers to a psychological attachment to the organization (e.g. Stumpf and Hartman [65], Meyer and Allen [54]). Organizational commitment has been studied by the past literature in sales force management and for employee turnover, finding a positive association with the likelihood of staying (e.g. Shore and Martin [63]). However, person-organization fit is distinct in that it represents more of a congruency between the salesperson and a selling organization.

\subsubsection{Combining Fit and Performance in a Dynamic Model for Turnover}

A fundamental assumption that underpins the identification of these two components is that they are additively separable and that they derive from different aspects of on the job activities. The direct utility of a salesperson staying is a function of these two components, with the future expected utility being considered over some time horizon. The modelling challenge is how to incorporate learning about these future utilities and how to use this to explain observed decisions about salespeople leaving or staying.

Figure 1 illustrates the conceptual framework. The stay/leave decision hinges on the net future benefits of staying with this organization. This decision must take into account that staying allows the salesperson to learn more about both their fit and performance with the incumbent organization (resolving uncertainty), and that the same decision can be made at any point in the future.

When a salesperson starts at a firm, they are assumed to be unfamiliar with the characteristics of the organization, and therefore how well they fit with the organization. Salespeople learn about their person-organization fit from information obtained from activities associated with open sales cases. They also learn about their success rate, which is operationalized as the ratio of successful sales cases closed divided by total sales cases closed (whether successful or not). In addition, vicarious learning (cf. observation learning, Zhang [68]) about performance occurs when they first begin their job with the organization, when they observe the distribution of success rates across other salespeople in the selling organization. Once they commence their job with the organization, however, vicarious learning is combined with information about their own success rate. Salesforce performance (Fig. 1, top left box) thereby represents prior beliefs 
Fig. 1 Conceptual framework underlying the dynamic model

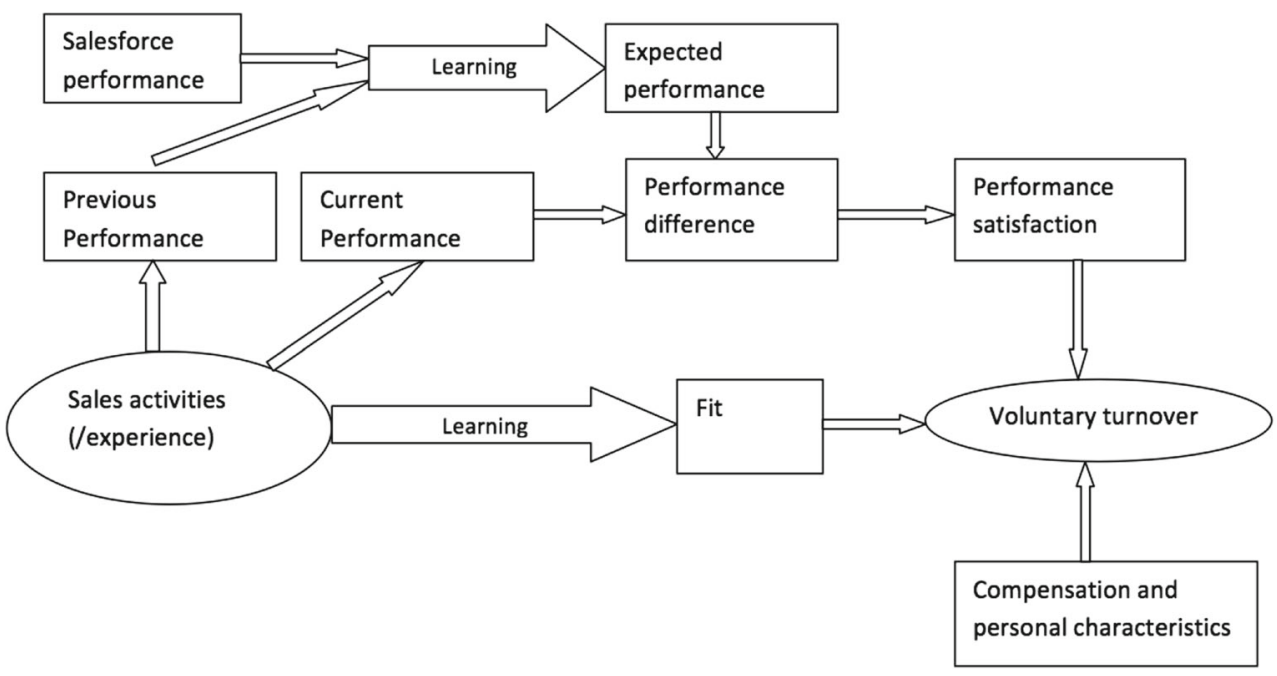

about performance from other salespeople. This is incorporated with previous performance results to come up with expectations about the current period performance. Current performance observations are used together with performance expectations and yield "performance satisfaction".

\subsubsection{Conceptual Difference between Performance and Fit}

For the purposes of our study, we draw a distinction between the constructs of (satisfaction with) performance and person-organization fit. We do so because they can be quite different. In other words, salespeople can fit very well with the organization, with different levels of performance. Conversely, it is conceivable that a person who has very high performance may leave because she fits poorly with the organization. It is this difference we want to examine in this study.

\subsubsection{Sales Performance and Job Performance Satisfaction}

We follow previous research (e.g. Bridges et al. [10]) and allow performance satisfaction to be a function of whether a salesperson met their personal expectations about performance. This is defined as the absolute deviation between (prior) expected performance and their observed performance in that period. We expect that performance that is below expectations will increase the likelihood of the salesperson leaving, in two ways. First, the expectation of future performance will fall. Interestingly, it will fall more for salespeople of shorter tenure than for salespeople who have been with the firm for longer. This is due to the nature of the updating rule. The variance of other salespeople's performance in the prior expectation will moderate this relationship. That is, if prior expectations are very tight, then falling short of performance is likely to provide little information. If prior expectations are diffuse, then falling short of performance will substantially lower their future expectations. A final point is on the expected symmetry of positive versus negative performance/expectations gaps. Bridges et al. [10] further discuss this phenomenon and expect that losses loom larger than gains. In other words, a negative performance shock was found to have a greater (and negative) effect on utility than a similar sized positive performance shock.

A more direct reason for including job performance satisfaction (by this definition) is to link it to increased compensation or rewards, especially in the context of commissionbased selling roles. High job performance satisfaction could be related to retention because this generates additional revenue [55] in any period. Our definition of expectations implies that this additional wealth is not expected in the future. Instead expectations, via the updating rule, are adjusted upward depending on how fixed their prior (to that date) expectations about their success rate is.

\subsection{Salesperson per Period Expected Utility}

For any period, we specify a salesperson's expected utility of staying as a function of observed performance versus their expected performance (e.g. Misra and Nair [55]) and a component representing person-organization fit. At any time, salesperson $j$ has a choice of whether to stay or leave the organization. Let $U_{j 1 t}$ denote the utility of staying versus $U_{j 0 t}$ which represents the utility of leaving. The utility of staying is:

$U_{j 1 t}=\alpha A_{j t}-r \alpha A_{j t}^{2}+\varphi g\left(S_{j t}\right)+X_{j t} \beta+\epsilon_{j t}$,

where $X_{j t}$ is observed and consists of salespeople compensation and demographics. The value of variables in $X_{j t}$ is assumed known for all time periods. The value $g\left(S_{j t}\right)$ is a function of their success rate $\left(S_{j t}=\frac{Y_{j t}}{n_{j t}}\right.$, with $Y_{j t}$ being 
successful sales leads closed, and $n_{j t}$ being total sales activities), and $A_{j t}$ is a measure of the person-organization fit. They provide utility to the salesperson at any time period $t$, and this is measured by the parameters $\alpha$ and $\varphi$, and risk aversion $r$. The salesperson is risk-averse if $r>0$, riskseeking if $r<0$, and risk-neutral if $r=0$. The parameter vector $\beta$ is utility weight parameters associated with covariates in $X_{j t}$. The stochastic term $\epsilon_{j t}$ is salesperson and time specific.

The variable $A_{j t}$ represents the latent/unobservable person-organization fit for salesperson $j$. This is salesperson and time specific, which implies that different salespeople may have different fit, and the same salesperson may have different fit over time. One organization has its characteristics, and each salesperson also has her own characteristics. If these match, person-organization fit will be good. Over time, both the organization and salesperson's characteristics are changing. Thus, the fit can change over time as well. The person-organization fit a salesperson perceives may differ from her true fit. As we discuss below, both are uncertain at any time and so we specify this as a function of random state variables.

Taking expectations with respect to an information set $Z_{j t}$ available to salesperson $j$ at time $t$, the expected utility is:

$$
\begin{aligned}
E\left(U_{j 1 t} \mid Z_{j t}\right)= & \alpha E\left(A_{j t} \mid Z_{j t}\right)-r \alpha E\left(A_{j} \mid Z_{j t}\right)^{2} \\
& +\varphi E\left[g\left(S_{j t}\right) \mid Z_{j t}\right]+X_{j t} \beta \\
& -r \alpha E\left(A_{j t}-E\left(A_{j t} \mid Z_{j t}\right) \mid Z_{j t}\right)^{2}+\epsilon_{j t} .
\end{aligned}
$$

We define job performance satisfaction at time $t$ as a function of the gap between expected (by the salesperson) versus observed performance both at time $t$ and $g\left(S_{j t}\right)=E\left(S_{j t}\right.$ | $\left.Z_{j t-1}\right)-S_{j t} . E\left(S_{j t} \mid Z_{j t-1}\right)$ is salesperson $j$ 's expected performance at the beginning of time period $t$ using information from until time period $t-1$. $S_{j t}$ is the salesperson's actual performance at the time period $t$. Here, we emphasize that at the end of time period $t$ (i.e. when the salesperson makes their decision to stay or leave), both of $E\left(S_{j t} \mid Z_{j t}\right)$ and $S_{j t}$ have been realized. There is no uncertainty about these values. This means that, for any future period, the expected difference is zero. For the present period, however, we have performance entering the utility function as the difference between expected (from period $t-1$ ) and current period $t$ performance. What enters the expected utility function is the surprise element of performance, or $E\left[g\left(S_{j t}\right) \mid\right.$ $\left.Z_{j t}\right]=E\left[S_{j t} \mid Z_{j t-1}\right]-S_{j t}$.

We assume the value function of leaving the company to be a time trend plus an error term: $E\left[U_{j 0} \mid Z_{j t}\right]=\gamma t+\epsilon_{j t 0}$ [19]. Any utility valuation is thereby scaled to the average outside opportunity of salespeople.

\subsection{Learning about Fit and Performance}

When they first begin with the sales organization, salespeople are uncertain about their person-organization fit. Accordingly, this uncertain state $A_{j 0}$ is drawn from a distribution for sales person $j$ at time $t=0$ being the first period they are hired at the firm. ${ }^{1}$ We assume that salespeople know the distribution of $A_{j 0}$, which is assumed to be i.i.d. normal (also identical over time) with mean $\mu_{A 0}$ and variance $\sigma_{A 0}^{2}$ :

$A_{j 0} \sim N\left(\mu_{A 0}, \sigma_{A 0}^{2}\right)$.

\subsubsection{Updating Person-Organization Fit from Sales Activities}

As they commence their selling job, salespeople learn about their fit with the organization from signals generated by onthe-job activities. The opportunity to learn from sales cases about their person-organization fit occurs in several ways. They learn whether there is a match between their skills, abilities and knowledge, and the attributes of the job and the values/culture of the organization. For example, during the early phase of their employment, salespeople begin to understand the type of cognitive and social skills that are necessary in their jobs, and over time these perceptions of work change [33]. Over time, the salesperson experiences various encounters and starts to develop an idea of the appropriate social skills required for the organization. For example, they will learn about how to deal with conflict with colleagues and customers, how inter-functional coordination occurs, and how to deal with supervisory feedback [32]. The importance of "socialization" for salespeople is examined by Dubinsky et al. [18] and Netemeyer et al. [59]. The socialization process involves the sales person learning about the social knowledge that is required to perform their sales role in the organization [66]. Salespeople also learn whether any citizenship behaviours [59] are required or rewarded in their organization.

Salespeople are encouraged to be customer oriented, which requires them to learn about the unique needs of the customers and to develop profitable relationships $[30,60]$. Furthermore, there is a shift towards key account management, with an emphasis on product customization, which involves both the external customer interface and the intraorganization interface with people who are responsible for product development [35]. Therefore, contemporary sales people have to learn about expectations of the various stakeholders, and their own abilities in this context, both important elements of person organization fit.

\footnotetext{
${ }^{1}$ Throughout, we will use $t$ to index time relative to the $j$ th focal salesperson beginning with the organization, rather than absolute time for the organization. Thus, $t=0$ for a salesperson $j$ corresponds to their start date.
} 
We distinguish the role of job-related activities from tenure in this context. As a salesperson's tenure increases, naturally the cumulative number of interactions will increase. This is captured in the learning process by allowing it to be driven by the on the job activities. This allows us to capture differences among any number of salespeople who start at the same time, but learn about organizational fit in different ways because of the number of sales activities they engage in.

Over time, the sales cases they handle provide salespeople with noisy signals that update their expectations about person-organization fit. This learning process allows them to make a time varying (uncertain) judgment of the extent of the match between their characteristics and the job attributes and the organization. This learning is organization specific, and leaving the organization to commence their career with another organization will require them to learn about their fit at a different organization.

This very simple structure of learning from salesrelated activities, is formally captured using the following specification. Based on the information set at time $t, Z_{j t}$, the salesperson forms an expectation over expected person-organization fit $E\left(A_{j} \mid Z_{j t}\right)$. When new information becomes available (from job activities proportional to the number of sales leads $n_{j t}$ ), they update this expectation using Bayes rule. As discussed above, each sales case handled provides observations about the organization's characteristics that provide salespeople with a noisy experience signal. We capture this by assuming any experience signal $k$ is drawn from a normal distribution with mean $A_{j}$ for salesperson $j$,

$W_{j t k} \sim N\left(A_{j}, \sigma_{W}^{2}\right)$.

We propose that the number of job-related activities is proportional to $n_{j t}$, the number of sales cases handled in any month $t$ by salesperson $j$. More specifically this is defined as the total number of sales cases closed that month, whether the case is successfully (i.e. results in a sale) or unsuccessfully closed (closed, but does not result in a sale). Over a period of time (e.g. 1 month, as in our application), if a salesperson receives $n_{j t}$ experience signals (i.e. sales cases) from their job activities, then the sample mean of experience signals is defined as

$W_{j t} \sim N\left(A_{j}, \sigma_{W}^{2} / n_{j t}\right)$.

The salesperson updates her prior belief about job attractiveness with the information acquired from experience signals to form a posterior belief about person-organization fit, using Bayes rule [17]. The salesperson-organization fit value thereby evolves as follows:

$E\left[A_{j} \mid Z_{j t}\right]=E\left[A_{j} \mid Z_{j, t-1}\right]+\gamma_{j t}\left(W_{j t}-E\left[A_{j} \mid Z_{j, t-1}\right]\right)$, where $\gamma_{j t}=\frac{\sigma_{j t}^{2}}{\sigma_{j t}^{2}+\sigma_{w}^{2} / n_{j t}}$. The perception error variance can be expressed as:

$$
\sigma_{j t}^{2}=\frac{1}{\frac{1}{\sigma_{j t-1}^{2}}+\frac{n_{j t}}{\sigma_{w}^{2}}} .
$$

The initial perception variance on person organization fit is $\sigma_{A 0}^{2}$. As the salesperson handles more sales cases (i.e. as $n_{j t}$ becomes large), the perception error converges toward zero. Ultimately, all salespeople in the organization will reduce their error variance over time. However, this model allows some salespeople to update more rapidly than others, depending on the number of sales cases they have the opportunity of handling.

\subsubsection{Expected Performance: How Salespeople Learn About Performance}

For expected performance, we use the success rate for any month $t$, anticipated by salespeople with a history of selling performance up to time $t$. For any time period, the success rate is operationalized as the proportion of sales cases closed, that result in a sale. Let $Y_{j t}$ equal the to number of sales cases that are successfully closed at time $t$ by salesperson $j$. Then the success rate observation for any month equals $\frac{Y_{j t}}{n_{j t}}$.

We assume that a salesperson who starts the organization $^{2}$ at time $t$ will have a prior about the success rate based on all historic data available across salespeople at time $t$, and call this $\mu_{j 0}$. We assume a beta prior distribution for this to be estimated on the basis of all observations available for incumbent salespeople: $\mu_{j 0} \sim \operatorname{beta}\left(a_{0}, b_{0}\right)$ with $a_{0}$ and $b_{0}$ to be estimated for each month of the observation period. The pdf for this prior being:

$f\left(\mu_{j 0} \mid a_{0}, b_{0}\right)=\frac{\Gamma\left(a_{0}+b_{0}\right)}{\Gamma\left(a_{0}\right) \Gamma\left(b_{0}\right)} \mu_{j 0}^{a_{0}-1}\left(1-\mu_{j 0}\right)^{b_{0}-1}$.

Once a salesperson commences her selling role with the organization, she sequentially updates using noisy signals about her own performance. ${ }^{3}$ The uncertainty in these signals reflects unobserved, unexpected shocks each month that influences performance. Over a period of time, however, they learn their success performance with the organization and may be greater or less than that of their colleagues. Each new salesperson entering the sales organization will update the prior (i.e. $a_{0}$ and $b_{0}$ ) used for any future salesperson.

\footnotetext{
${ }^{2}$ The initial prior distribution of the success rate faced by salesperson $j$ (i.e. $\mu_{j 0}$ ), will vary over the observation period of the entire selling organization and represents the distribution of performance across salespeople.

${ }^{3}$ Details of the derivation of these distributions are given in the online appendix.
} 
We assume that the sales cases are allocated to salespeople exogenously by a sales lead generation system and are known by the salesperson at the beginning of each month. Such an assumption makes sense to the extent that much of the variation is from external demand, perhaps influenced by a firm's marketing activities. This means that the only uncertainty is about what proportion of sales leads will close successfully. Clearly, this assumption could be relaxed by, for example, allowing the sales manager to allocate leads according to either the potential effort or productivity levels of individual salespeople.

At the end of each month $t$, salesperson $j$ observes $Y_{j t}$ out of $n_{j t}$ cases successfully closed. These signals are drawn from a binomial distribution. The state variable (used to forecast the number of sales cases successfully closed for month $t+1$ ) is updated after observing $Y_{j t}, n_{j t}$ as follows:

$$
\mu_{j t} \mid a_{j 0}, b_{j 0}, n_{j t}, Y_{j t} \sim \operatorname{beta}\left(a_{j 0}+\sum_{\tau=1}^{t} Y_{j \tau}, b_{j 0}+\sum_{\tau=1}^{t}\left(n_{j \tau}-Y_{j \tau}\right)\right),
$$

so that, at any time $t$ with the distribution for $\mu_{j, t-1}$ available from the previous period, the beta-binomial for $Y_{j t}$ is:

$f\left(Y_{j t} \mid \mu_{j, t-1}, n_{j t}\right)=\left(\begin{array}{c}n_{j t} \\ Y_{j t}\end{array}\right) \frac{\operatorname{beta}\left(a_{j 0}+Y_{j t}+\sum_{\tau=1}^{t-1} Y_{j \tau}, b_{j 0}+\left(n_{j t}-Y_{j t}\right)+\sum_{\tau=1}^{t-1}\left(n_{j \tau}-Y_{j \tau}\right)\right)}{\operatorname{beta}\left(a_{j 0}+\sum_{\tau=1}^{t-1} Y_{j \tau}, b_{j 0}+\sum_{\tau=1}^{t-1}\left(n_{j \tau}-Y_{j \tau}\right)\right)}$.

Thus, the expectation regarding future performance at the beginning of any period is based on the number of sales leads open for the focal month, multiplied by the expected value of the success rate for that month. Formally, this can be written as:

$$
E\left[Y_{j, t+1} \mid \mu_{j, t}, n_{j t+1}\right]=\frac{n_{j, t+1}\left(a_{j 0}+\sum_{\tau=1}^{t} Y_{j \tau}\right)}{a_{j 0}+b_{j 0}+\sum_{\tau=1}^{t} n_{j \tau}} .
$$

\subsection{The Decision to Stay as a Dynamic Optimization Problem}

Given the per period utility function in Eq. 2, we now consider the dynamic problem wherein a salesperson $j$ decides whether to stay or leave the company at time $t$ $(t=1,2, \ldots, T)$, with the corresponding objective to maximize her expected present discounted value. Salesperson $j$ at time $t$ makes a decision about whether she will stay in the company $\left(s_{j t}=1\right)$ or not $\left(s_{j t}=0\right)$, based on her expected net present utility given by the current state of the information set. If the salesperson decides to stay at time $t$, she gets an expected utility of $E\left(U_{j 1 t} \mid Z_{j t}\right)$ and will have to make a decision again at period $t+1$. If she leaves the company, she receives an expected utility of $E\left(U_{j 0 t} \mid Z_{j t}\right)$. Using the Bellman equation [7], the salesperson's value function can be expressed as follows:

$V_{j 1 t}=E\left(U_{j 1 t} \mid Z_{j t}\right)+\delta E\left(V_{j t+1} \mid s_{j t}=1\right)$,

where $\delta$ is a discount factor for future utility. The decision procedure is, at the end of each period (i.e., each month), a salesperson makes her decision to stay or leave, based on her experience/utility of this period in the organization. Our primary interest is in the salesperson's decision to stay or leave the focal organization. Once the salesperson leaves the organization, they enjoy a net present utility assumed to be fixed. The interest is only on salespeople who leave the company, and we are not specifically stating any assumption about the outside option, rather fixing it to some value. ${ }^{4}$ The Bellman captures the feature that, when making a decision, a salesperson considers benefits from this period and expected benefits from all future periods. Define $E\left[U_{j 1 t} \mid Z_{j t}\right]$ as the deterministic part of the expected utility. We assume the error term $\epsilon_{j t}$ in Eq. 2 is iid Gumbel, so the probability that salesperson $j$ stays in the company at time $t$ is

$\operatorname{Pr}\left(s_{j t}=1 \mid Z_{j t}\right)=\int \frac{\exp \left(E\left[U_{j 1 t} \mid Z_{j t}\right]+\delta E\left(V_{j 1 t+1} \mid s_{j t}=1\right)\right)}{\exp \left(E\left[U_{j 0 t} \mid Z_{j t}\right]\right)+\exp \left(E\left[U_{j 1 t} \mid Z_{j t}\right]+\delta E\left(V_{j 1 t+1} \mid s_{j t}=1\right)\right)} f(v) d v$.

Here, $v$ is the perception error (i.e. the difference between the real and perceived person-organization fit), which is not directly observable to the researcher. Thus, we need to integrate it out of this probability. Given there is no closed form solution to this integral, we use numerical simulation. Once we get the probability that a salesperson stays, we can derive the probability that she leaves (i.e. $\operatorname{Pr}\left(s_{j t}=\right.$ $\left.\left.0 \mid Z_{j t}\right)=1-\operatorname{Pr}\left(s_{j t}=1 \mid Z_{j t}\right)\right)$. The probability that

\footnotetext{
${ }^{4}$ This model can also be used to study sales force turnover across different organizations. This could be a powerful extension to our model if data were available across multiple sales organizations.
} 
a salesperson will leave or stay at time $t$ depends on not only the expected utility at time $t$, but also how the decision will influence the information about person-organization fit available to him at time $t=1$, which will certainly have some impact on the expected utility at time $t+1$. For example, although a particular salesperson's expected utility at time $t$ is low, she may choose to stay because she really wants to learn more about both fit and selling outcomes. It is plausible, however, that the salesperson may not have full information about fit but decides to leave because they are reasonably sure their success rate is low. Thus, the combined effect of fit and success rate is what is important.

\section{Data and Estimation}

\subsection{Data Description}

Our application is in the context of the selling organization of a large multinational software company. This companymainly sells its products to business users in North America. The main task of salespeople in this organization is to sell to their potential customers from potential customer lists and cold calling. Most of the sales are based on leads, although for smaller firms, there may be some cold calling. These lists are obtained from several sources (e.g. purchased from information vendors). Much of the variation is due to the volatility of demand and due to geographical territorial allocations. Our data is at the individual salesperson level and therefore it identifies the specific salesperson that handles each case.

The data set for recruitment/resignation indicates whether and when a salesperson left the company. We only keep the salespeople who joined in the available observation window and do not consider (censored) data from salespeople for which we do not observe their starting date. As a result, we observe each salesperson's entire employment history within the organization. Much of the literature uses the metric of intention to quit or leave for measuring turnover (e.g. Boles et al. [9]). This has been shown to be a good, but partial, explanation of actual turnover. Since our study is about salespeople voluntary turnover, we remove from our sample salespeople who were forced to leave. We only deal with sales cases that have been closed (i.e. won or lost). To study salespeople's turnover decisions, we aggregate the data to monthly level. Salespeople are assumed to decide, at the end of each month, whether to stay or leave the company based. This decision is based on their full information set at the end of each month.

The sales activity data set includes detailed information about the software of interest, customer name, budget available, status of sales lead (i.e. open, won and lost) and the time when the case was opened and closed. We also obtained data on each salesperson's average salary and demographic information. As some of the salespeople have already left the company, we were not able to obtain detailed salary data for everyone. Thus, the salary used here is the average salary during our data period. The demographic information obtained includes gender and marital status.

Combining the three data sets (i.e. recruitment/ resignation, sales activities/performance and salary/ demographic information), we have valid information for 157 salespeople. Our observation window is from July 2003 to May 2006 or 34 months. Of the 138 salespeople, 48 left the company during the observation window. The average age is 28 years, $74 \%$ are male and $31.9 \%$ of them were married. The average tenure length is 12.75 months. Summary statistics can be found in Table 1. In addition, the cumulative number of sales leads to sales people who stayed is 48 , and sales people who left is 41 . Similarly, we find that the success rate for salespeople who left $(8 \%)$ is significantly and substantially lower than for salespeople who stayed (34\%). Together, this suggests that there is a negative association between performance and turnover, but this is not indicative of the simultaneous role that person-organization fit plays.

\subsection{Estimation Procedure}

In principle, the estimation of our model is very similar as the one used in a standard discrete choice model. We need to get an expression for the utility associated with each alternative (i.e. stay or leave). But the challenge in a dynamic model is that we have to get an expression of the expected future utility (i.e. we have to compute the value function specified in Eq. 12). The dynamic model is solved using simulation and interpolation [19,37]. As this is a backward solving method, the decision horizon $T$ has to be finite. Because of the computation burden, $T$ cannot be set as too large [19]. In our study, we set the horizon $T=50$ months

Table 1 Descriptive statistics

\begin{tabular}{lllll}
\hline Variable & Mean & Std. dev. & Min & Max \\
\hline Success rate & 0.2094 & 0.3058 & 0 & 1 \\
Cases per period & 4.9062 & 4.1952 & 1 & 37 \\
Salary & 3.8061 & 0.7934 & 2.5 & 8 \\
Gender (1; male) & 0.7389 & 0.4407 & 0 & 1 \\
Age & 28.1656 & 2.4175 & 23 & 35 \\
Marital status (1; married) & 0.3185 & 0.4674 & 0 & 1 \\
Education (1; post-grad & 0.9554 & 0.2071 & 0 & 1 \\
$\begin{array}{l}\text { or equivalent) } \\
\text { Tenure length }\end{array}$ & & & & \\
with the company & 12.7516 & 6.6907 & 3 & 33 \\
\end{tabular}


or around 4.5 years. At time $T$, the value function is simply $V_{j}\left(Z_{j T}\right)=\max \left\{E\left[U_{j 0} \mid Z_{j T}\right], E\left[U_{j 1} \mid Z_{j T}\right]\right\}$.

\subsubsection{Likelihood Function}

From Eq. 13, the likelihood function for salesperson $j$ is,

$$
L_{j}\left(\Omega \mid Z_{j 1}\right)=\prod_{t=1}^{T} \operatorname{Pr}\left(s_{j t}=0 \mid Z_{j t}\right)^{\left(1-s_{j t}\right)} \operatorname{Pr}\left(s_{j t}=1 \mid Z_{j t}\right)^{s_{j t}},
$$

where $\Omega$ is the parameter vector to be estimated. As a result, the likelihood function for the $J$ salespeople is

$$
L L\left(\Omega \mid Z_{1}\right)=\prod_{j=1}^{J} L_{j}\left(\Omega \mid Z_{j 1}\right)
$$

In this likelihood function, salespeople are assumed to be identically distributed and conditionally independent. The condition here being anything they learn about performance from other sales people. As indicated, it is reasonable that they learn about some things from other sales people, and we inject this into their learning by allowing them to form priors based on this information. However, we argued that they don't learn about their own success rate from other salespeople's past performance, so unless they get utility from being better than the average salesperson, and there is a lot of variability each month in this average, the only thing that matters is their own observed historic performance. The log-likelihood function is evaluated using the method of simulated maximum likelihood.

The state variables used in our study are perceived person-organization fit, salespeople expected performance, salespeople salary, gender and marital status. Of these, only perceived person-organization fit and salesperson expected performance are changing over time. Therefore, in the dynamic model, salespeople need to have an expectation of them in the future periods. In this study, we want to check whether high salaried salespeople are more likely to leave or low salaried people are more likely to leave. So, we created a dummy variable based on the average salary data we have: 1 for top $25 \%$, and 0 otherwise. For the results we present, we fix the value of the discount factor at 0.9 .

\subsection{Identification}

The parameters to be estimated include the parameters of salespeople's initial expection about their own performance $\left(a_{j 0}, b_{j 0}\right)$, the prior mean of the unobservable person organization fit $\left(\mu_{A 0}\right)$, the initial variability of the personorganization fit $\left(\sigma_{A 0}\right)$, the learning variability $\left(\sigma_{w}\right)$, the risk aversion coefficient $(r)$, utility weight parameters associated with salary and demographics $(\beta)$, and time trend parameter $(\gamma)$ and the time discount factor. The parameters for each salesperson's distribution on initial expections about their future performance $\left(a_{j 0}, b_{j 0}\right)$ are determined by when a salesperson joined the company. The data for the periods before the salesperson joined the company was used to identify these two parameters for each salesperson. For example, if a salesperson joined in month 4 , we use the data from the first 3 months to estimate the two parameters for her. Thus, salespeople who joined the company at different times have different initial expectation parameters. The prior mean of the unobservable person-organization fit is identified by the initial salespeople turnover rate. To separate the initial prior mean from the random error term, we need several turnover cases in the initial period. In other words, the initial steady turnover rate of the salespeople can identify the prior mean. Otherwise, $\mu_{A 0}$ cannot be separated from the random error $[19,58] .5$ The prior variance of the unobservable personorganization fit $\left(\sigma_{A 0}\right)$ is set to one [68]. The actual value of initial variance is not important in our study, since this will not influence our substantive results. Similarly, we set the utility weight associated with the unobservable fit $(\alpha)$ to be equal to one. The variability of the experience signal $\left(\sigma_{w}\right)$ is identified by the rate of fluctuation of the salespeople's turnover converging to the steady state and the learning experience from historic performance. Specifically, the difference between initial and long-run steady salespeople turnover rates can identify the learning parameter. The evolution of salespeople turnover rates, $\sigma_{w}$ and $\mu_{A j}$, identify the risk coefficient $r$. The $\beta$ parameters are identified by the relevant explanatory variables.

We set the value of the discount factor at .9 because of the difficulty in estimating the discount factor [19]. But we also estimate the model with two different discount factor values: .85 and .95 . The insights from these results are similar as to the discount factor of 0.9 , and we ommit the full details.

\section{Results}

We first reflect on some summary statistics about the apparent association between the length of time salespeople stay with the organization, and their observed selling performance, as measured by success rates (refer to Table 2). In our sample, 33 salespeople resigned during the period of observation (of 24 months). Most leave within 7 to 12 months, but there is a sizeable group that leaves within 6 months. Tracking their success rates, we see that salespeople who leave within 6 months and within 7 to 12

\footnotetext{
${ }^{5}$ Here, we use the first 5 months as the initial period. As shown in Table 2, there were four salespeople left during this initial period.
} 
Table 2 Salesforce turnover descriptive statistics

\begin{tabular}{|c|c|c|c|c|}
\hline & Total & $\begin{array}{l}\text { Within } 6 \\
\text { months }\end{array}$ & $\begin{array}{l}\text { Within 7-12 } \\
\text { months }\end{array}$ & $\begin{array}{l}\text { Within 13-24 } \\
\text { months }\end{array}$ \\
\hline Number & 33 & 4 & 20 & 9 \\
\hline $\begin{array}{l}\text { Percentage of } \\
\text { salespeople who left }\end{array}$ & & 12.12 & 60.61 & 27.27 \\
\hline $\begin{array}{l}\text { Percentage across } \\
\text { all salespeople }\end{array}$ & & 2.90 & 14.49 & 6.52 \\
\hline \multicolumn{5}{|l|}{ Sales performance: } \\
\hline Success rate (all salespeople) & & 0.297 & 0.223 & 0.135 \\
\hline Success rate (salespeople who left) & & 0.200 & 0.201 & 0.248 \\
\hline
\end{tabular}

months have a success rate substantially below that of their colleagues. For salespeople who stayed longer (taking 1324 months to leave), we see this reverse entirely. The immediate message from these results is that salespeople who leave in the short run do so because they observe low performance. The curious finding is that salespeople who stay longer tend to only leave if their performance is high. What is masked by these results is the unobserved person-organization fit. We now examine results that can shed some light on this important component of turnover.
We fit various specifications for the models using Eqs. 13 to 15 to our data sample (refer to Table 3). We focus on the main results, reported in the first column of Table 3 (model 1), and discuss the alternative specifications in a later subsection.

The parameter estimates correspond to covariates that raise the discounted long-term utility of staying with the organization, so positive estimates indicate reduced effects on salesforce turnover. The estimate for time trend is positive. This measures the time since any individual sales

Table 3 Selected estimation results for different specifications of the dynamic model

\begin{tabular}{|c|c|c|c|c|c|c|c|c|}
\hline & \multicolumn{2}{|l|}{ Model 1} & \multicolumn{2}{|l|}{ Model 2} & \multicolumn{2}{|l|}{ Model 3} & \multicolumn{2}{|l|}{ Model 4} \\
\hline & Est & t-stat & Est & t-stat & Est & t-stat & Est & t-stat \\
\hline Intercept & & & & & $0.442^{* * *}$ & 5.228 & $0.520^{* * *}$ & 7.225 \\
\hline $\begin{array}{l}\text { Learning variabi- } \\
\text { lity/ utility weight } \\
(\alpha)\end{array}$ & $0.464^{* *}$ & 2.436 & $0.476^{* * *}$ & -2.917 & & & & \\
\hline $\begin{array}{l}\text { Prior attractive- } \\
\text { ness }\left(\sigma_{0}\right)\end{array}$ & $-0.317^{* *}$ & 2.150 & $-0.297^{* *}$ & -2.255 & & & & \\
\hline $\begin{array}{l}\text { Positive perfor- } \\
\text { mance }\end{array}$ & $6.834^{* *}$ & 2.048 & & & $7.513^{* *}$ & 2.250 & & \\
\hline $\begin{array}{l}\text { Negative perfor- } \\
\text { mance }\end{array}$ & 0.975 & 0.724 & & & 1.339 & 1.055 & & \\
\hline Salary & $0.221^{* *}$ & 2.461 & $0.193^{* *}$ & 2.398 & $0.190^{* *}$ & 2.399 & $0.166^{* *}$ & 2.320 \\
\hline Gender & $-0.118^{*}$ & 1.742 & -0.103 & -1.709 & -0.093 & -1.495 & -0.073 & -1.323 \\
\hline Marital Status & 0.046 & 0.680 & 0.040 & 0.656 & 0.007 & 0.113 & 0.006 & 0.101 \\
\hline $\begin{array}{l}\text { Risk coefficient } \\
(r)\end{array}$ & $-1.667^{* * *}$ & 2.967 & $-1.801^{* * *}$ & -3.361 & & & & \\
\hline Time trend & 0.769 & 1.411 & 0.695 & 1.274 & $1.360^{* * *}$ & 2.583 & $1.424^{* * *}$ & 2.902 \\
\hline LL & -135.8022 & & -140.6272 & & -149.5394 & & -142.781 & \\
\hline
\end{tabular}

Key: ${ }^{*} p<0.1 ; * * p<0.05 ; * * * p<0.01$ 
person started their job. In the management literature, this is often referred to as salesperson "tenure". In all models estimated, we find that the tenure coefficient is positive and statistically significant. Beyond the effects of performance, person-organization fit and demographics, this result suggests that salesperson turnover is negatively related to their tenure. We recognize that since we allow new salespeople to be added to the risk set that this provides a good approximation of the baseline hazard of a salesperson leaving (see Fader and Hardie [21] for a similar result in the context of customer retention analysis).

The learning variability parameter is positive and statistically significant, providing evidence that salespeople are learning about their person-organization fit via the handling of sales cases. The prior attractiveness parameter is negative and statistically significant, indicating that salespeople who have more diffuse prior expectations about the organization are less likely to stay for a longer time.

The estimated risk coefficient is negative and statistically significant, which we interpret to mean that salespeople are generally risk seeking. This result suggests that higher perceived person organization fit variance can actually attract salespeople to stay. At first glance, this result seems counter intuitive. But in the specific context we are studying, salespeople turnover, we provide the following explanation. Initially, shortly after commencing their selling role, salespeople try to learn about whether this is the right job for them or not, in terms of both their person-organization fit and their expected success performance. They are therefore less likely to leave before they have more confidence in their belief about the level of the attractiveness of staying with the organization.

Recall that the handling of more sales activities does not necessarily imply a good fit between the salesperson and organization. It is highly plausible that, from the handling of more sales cases, a high performance salesperson learned that this is not the right job for reasons related to personorganization fit (e.g. not challenging enough, no growth opportunity and organization culture mismatch), rather than their performance.

After we have controlled for the fact that sales people may learn from their sales activities about personorganization fit, we find a significant negative relationship between expected performance and turnover. The interpretation of this result is that good performers are more likely to stay. Recall that it is performance above or below expectations, as defined by a sequential learning rule, that alters to utility and changes the likelihood that a salesperson stays. We find that higher than expected success for a given month increases the likelihood that the salesperson stays. Surprisingly, we do not find evidence that negative performance shocks (below expectations) increases the likelihood a salesperson will leave.
Our results show that there is a significant negative relationship between compensation of salespeople, and turnover, which is consistent with much of the extant literature. We find that the two demographic factors we consider here, gender and marital status, do not have a significant impact on turnover.

\subsection{Alternative Models}

In Table 3, we also include the estimation results for several alternative specifications. Model (1) is the full model as described above, with person-organization fit, salesperson performance as well as all time invariant covariates included. In model (2), we ommit the component for salesperson positive and negative performance difference. In model (3), we assume that salespeople know their fit with the organization, and that it is constant over time. For model (3), we retain the positive and negative performance difference variables in the model. In model (4), we ommit both the salesperson learning and performance difference components. This is identical to model (3) in that salespeople are assumed to know their person-organization fit throughout their tenure at the selling organization. Table 3 also reports log-likelihood values of the four models. It shows our model fits better than the other models. We also run likelihood ratio tests, and the results also support it $(\mathrm{p}<.01)$. We find that the role of tenure becomes statistically significant, suggesting that the organizational fit may be captured by tenure if ommitted from the model explicitly.

Recall that we fixed the discount factor to 0.9 . In the online appendix, we report some results where we run the full specifications (Model 1) for different discount factors (i.e. 0.8 and 0.95), which indicates that the estimates are robust to different assumptions about the extent to which salespeople are forward looking. We also examined different time horizons $(\mathrm{T}=100)$ and find similar results. We also tried a model that controls for salesperson heterogeneity in their propensity to stay. For this, we estimated a latent class version of our model [28, 36]. We tried several different classes, but the models tested suggested there was just one class (according to Akaike information criterion and Bayesian information criterion).

\section{General Discussion}

\subsection{Salespeople Performance and Turnover}

Our results improve our understanding of how salesperson performance and voluntary turnover are related. Past work has shown conflicting results on the relationships between performance and salespeople voluntary turnover [10]. Are high performers or low performers more likely to leave? 
We argue that it is not solely the success rate influencing the turnover directly. Salespeople also learn about the fit between them and the organization from their sales activities. More importantly, it is not just the successful sales cases closed that the salesperson learns about, suggesting that sales managers should not just use a salesperson's performance to predict her intention to leave. To evaluate the impact of a change in performance, we run a policy experiment on the basis of our results. We add one more successfully closed case $\left(Y_{j t}+1\right)$ per time period, for each sales person. Note that this also augments the sales leads $\left(n_{j t}\right)$ by one. The purpose of this is to look at what happens when we add a "high quality" sales lead to the activities of each sales person, rather than just adding sales leads with unknown consequence to the success rate. The result of this policy is to provides salespeople with extra information both about person-organization fit, and it will raise the positive performance shock, leading to higher job satisfaction. The result of this experiment is graphically depicted in Fig. 2. On the vertical axis, we plot the time $t$ value of the utility of staying and the horizontal axis we plot counterfactual utility over time. We immediately observe that there is no unambiguous direction to this policy, an additional sales case could have either a positive or negative impact on the utility of staying. This further explains why there is conflicting evidence on the association between performance and voluntary turnover. In some cases, the additional case increases the likelihood, in other cases, it decreases the likelihood of the salesperson staying (Fig. 2).

Our results also show that the difference between expected performance and actual performance will influence salesperson satisfaction, which will influence their intention to leave. Salespeople may form their expectations in different ways such as based on their previous performance. In this model, salespeople update their expectation based on their previous performance in a Bayesian way. In practice, sales managers may influence how salespeople form their expectation. For example, expectations could be influenced by setting sales quotas. On the one hand, it is

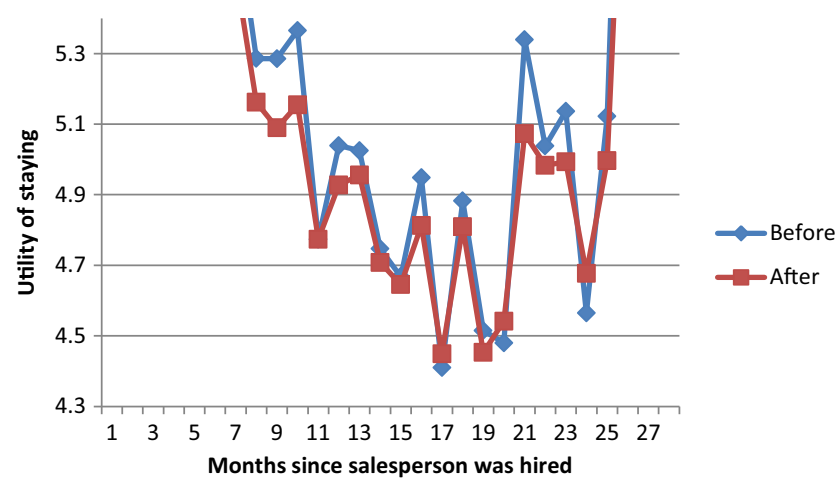

Fig. 2 Effect of adding one successful case to each period good to always set a slightly higher sales target in order to encourage salespeople to perform better. On the other hand, if the target is too high, then salespeople will have difficulty meeting their target. These deviations from expectations will influence their satisfaction and therefore their intention to leave.

\subsection{Salespeople Performance vs. Person-organization Fit}

A question that arises from our results is how different are sales performance and person-organization fit? Because our model allows us to estimate both performance and the fit between the organization and salespeople, we can examine the association between salespeople performance and fit (see Fig. 3). From the figures, we can see there is no clear relationship between salespeople fit and performance for both salespeople who stayed and left. We confirm this using a regression between fit and performance and find no evidence of an association between performance and fit.

To further show the different impact of fit and job performance satisfaction, we calculate the proportional contribution of fit and performance satisfaction in salespeoples utility of staying in the company. This is visually displayed as a function of time in Fig. 4. For fit, we use the results from Model 1 and calculate the net present value of the utility of staying. We examine how much is driven by the person organization fit component, which includes both the mean and the variance of fit. For performance satisfaction, we use the positive difference between observed performance and expected (at the beginning of each time period) performance. On average, fit and job performance satisfaction contribute 16.28 and $15.51 \%$ of the total utility. What is interesting is that over time the relative proportion of these two components changes. Fit initially has a much larger role to play in the first year, than does the performance gap. After the first year, however, performance starts to play a much larger relative role. This suggests that, given the person-organization fit is high for any salesperson, the higher selling performance is not as critical a factor to keep a salesperson from leaving. However, after the first year, and particularly toward the beginning of the second year, it is much more important to concentrate on sales performance. These findings carry strong sales management implications for the temporal allocation of sales leads of varying levels of quality.

\subsection{Sales Management: Setting Expectations at Recruitment}

In our model, salespeople are able to observe the full performance distribution of the salesforce, prior to beginning their selling role. The person-organization fit, however, is more subjective and so broad priors are assumed to exist 
(a) Salespeople who stayed

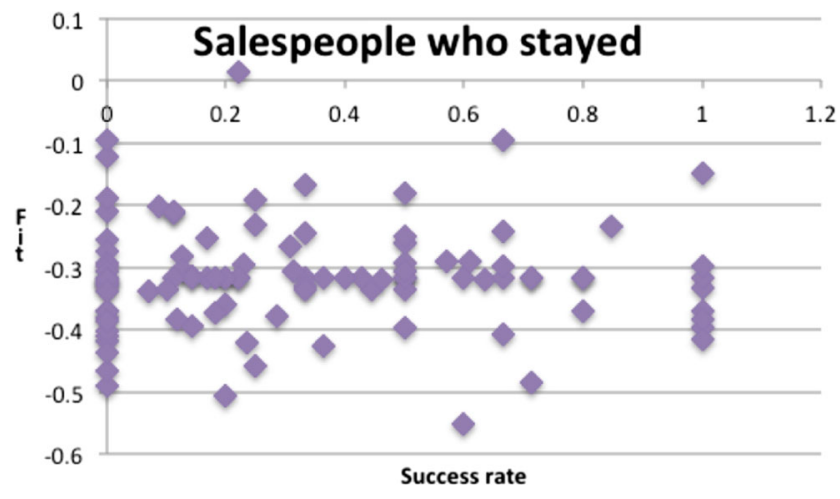

(b) Salespeople who left

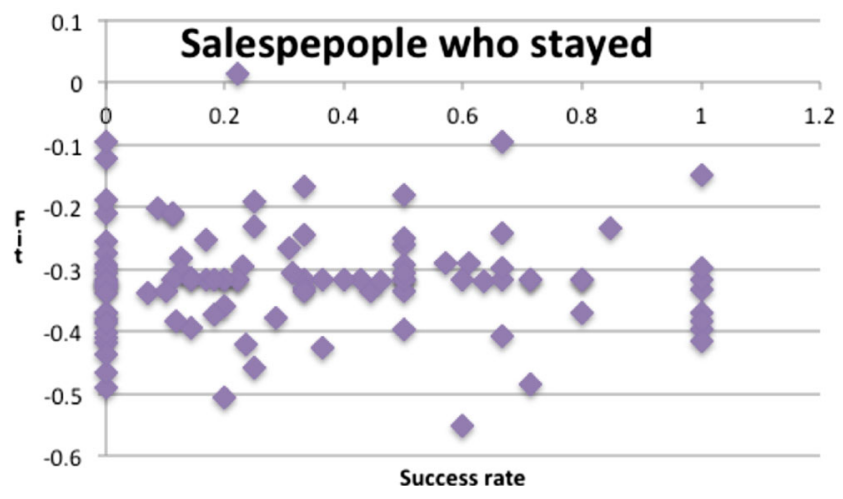

Fig. 3 Person organization fit versus performance

on this. An important implication arising from our results is the question of whether sales managers should (if they can) influence prior expectations about person-organization fit for newly recruited salespeople. In the context of our model, at the time the salesperson is being recruited, should the firm set a higher prior on fit (i.e. higher mean)? We can examine this question by studying how quickly salespeople learn about their true fit with the organization. A higher mean sets a higher expectation regarding fit, so we may a priori expect that this will act as a buffer on a salesperson leaving. We

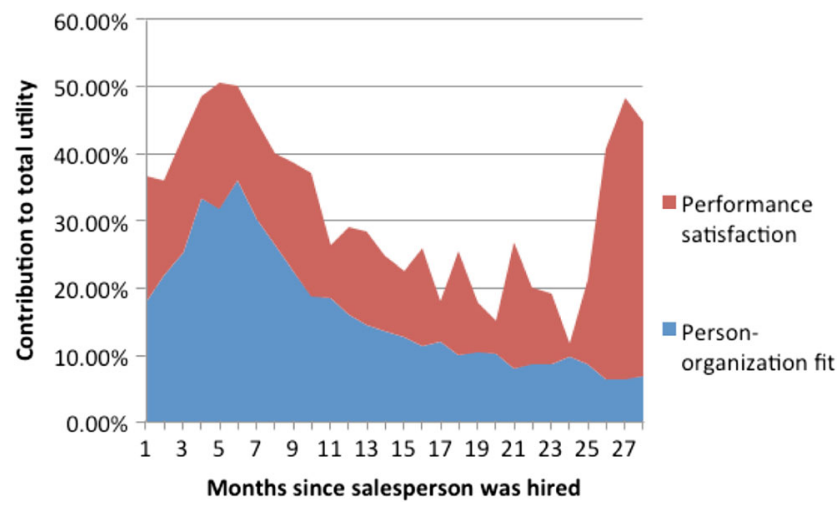

Fig. 4 Contribution to utility of satisfaction and fit

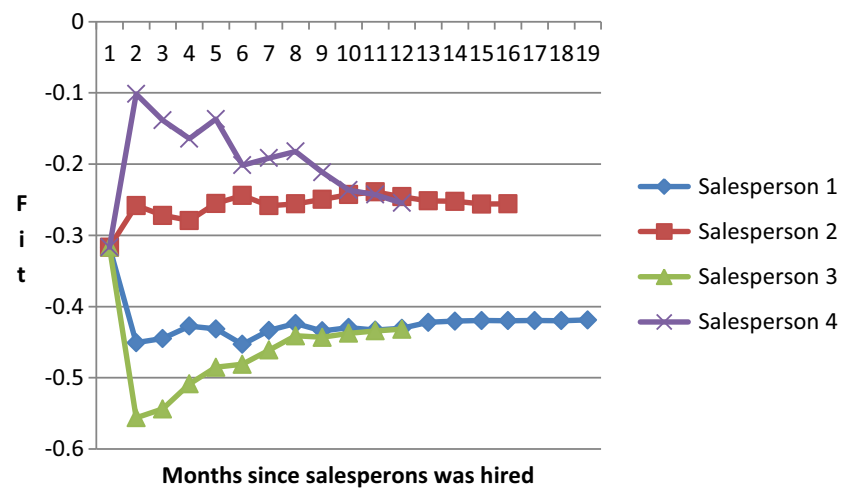

Fig. 5 Fit trajectories for several salespeople who started at the same time

note that, from our descriptive results, we observe very few salespeople who leave during this "honeymoon" period.

Our results suggest that it is not likely to be very fruitful to set these higher expectations, since salespeople will quickly find their true person-organization fit regardless of how diffuse their prior is. The posterior state for fit can be higher or lower. In Fig. 5, salespeople 1 and 2 stayed with the organization, while 3 and 4 are salespeople who left. Salespeople 2 and 4 have higher fit than salespeople 1 and 3 , but one left and the other stayed. This means besides the perceived fit, other factors such as satisfaction and compensation will also influence salespeople turnover decision. So, it is not the case that a salesperson who has a higher fit with the organization will definitely stay. Sales managers also need to pay attention to them.

\subsection{On Future Research Building on our Framework}

The goal of this study was to demonstrate how one could incorporate both person-organization fit and satisfaction with job performance, in a model that considers forward looking behaviour by salespeople who face the decision whether to stay or leave a sales organization. We have demonstrated the value of this model and suggested the insight that perhaps fit is more important initially than performance (with these roles reversing with tenure). Much work in this area could improve the reliability of this finding, and test its validity relaxing a number of assumptions we have had to make in our model development.

1. Prior beliefs - we have held that prior beliefs are developed by incoming salespeople by observing the distribution of incumbent sales people's success rates. An interesting direction to this research would be to include how prior beliefs are held in a heterogenous way by individual sales people. Such beliefs could be based on past experience with other (perhaps similar) selling organizations. 
2. Success rates and compensation - we did not have information on either sales values (which we would need for every sales lead, not just the successful ones), or compensation structures tied to successful closed sales cases. The availability of such data would be of value in examining how compensation itself could be tied to sales performance.

3. Other factors that influence organizational fit and success rate - a good direction would be to examine how salespeople learn about their performance and about organization fit may depend on other factors. A challenging question would be how these can be incorporated in the learning mechanisms for each of fit and performance. However, there may be useful variables that can be included here, e.g. consider induction procedures, mentoring programs, team building exercises or training exercises. Obviously, some would have an impact on both organization fit and performance, while others could be targeted to improve either one.

4. Salespeople's effort levels - clearly there is link between success rate and effort levels, which we have acknowledged in constructing our model. This link could also reasonably be construed (though perhaps causality is more balanced) for a sales employee's person-organization fit.

5. Observational learning - a really interesting aspect of considering success rates and organizational fit as state variables (to be learned about) is how they learn from other salespeople. We incorporated the information from other salespeople in the priors and during each month after they are hired, salespeople update their belief about future performance based on their own performance and job activities. A good direction for research is therefore to examine whether there is further observational learning that could perhaps even bias their perceptions of performance. For example, if a salesperson performs badly, and observes others performing really well, this could make that salesperson more likely to stay with the organization (to the extent that they are inspired by others). On the other hand, they would end up being in the lower part of the distribution and experience negative utility of being among a group of people who are outperforming the focal salesperson.

\section{Conclusion}

In sales management, substantial performance improvements can be brought about by reducing voluntary turnover of effective salespeople. In many companies, salespeople turnover rate is very high, with significant implications for firm profitability [13, 24, 48, 57]. This is a more general problem than just sales employees. Startlingly, the U.S.
Department of Labor figures suggests that the monetary costs of hiring a new employee may be as high as a third of the person's salary, and replacing a sales person can cost up to 2.5 times the annual earnings of the sales person who left the organization [12]. Direct costs of employing a new salesperson is about $200 \%$ of the salary [27]. It is also important to find ways to keep salespeople for longer, if the goal is for the sales function to become more relationship oriented [2], and as the market demands a customer focused strategic approach [42]. This presupposes that such salespeople are the "high performing" salespeople, who are particularly difficult to retain since they can easily find other selling roles. Understanding the processes and factors that influence sales force turnover is therefore of critical importance to both academics [9] and practitioners [62].

Central to retaining high performing salespeople is how they adapt to the organization, learning from selling-related job activities about their fit and performance in the selling organization. Our structural model is innovative in the domain of sales force management literature for a number of reasons. First, we use a dynamic (forward looking) model to capture the combined effect of performance and person organization fit, on salespeople's turnover decisions. We highlight that salespeople may stay in the organization even though their current utility of staying may be very low. This apparent paradox is resolved by virtue of their strategic view of longer term utility of staying with the selling organization. Second, the dynamic model could provide a unique mechanism for the real-time monitoring of salespeople's learning through experience, calibrated on a selling organization's historical records. This would reduce the costs of obtaining further information to estimate salesperson learning, for example, by the use of surveys. Third, we propose a conceptual framework that challenges current knowledge (e.g. Lee et al. [47], Lee and Maurer [44], Lee et al. [46], Mitchell and Lee [56]) about the longitudinal relationship between salespeople turnover and performance.

As a closing point, it has been recognized that it is not necessarily the case that all voluntary turnover is detrimental to the organization. Functional turnover being defined as when the lowest performers leave [1], whilst dysfunctional turnover happens when the higher performers leave, taking with them knowledge [5]. We would expand this classification to include the role of person-organization fit. In other words, we would make the case to broaden the definition of functional turnover, to include individuals who do not fit well with the organization, even if that means that they are of higher performance. Beyond that, it is an open question as to whether it is an advantage to the organization whether employees who fit well with the organization but perform poorly (below average) were to leave. 


\section{References}

1. Abelson MA, Baysinger BD (1984) Optimal and dysfunctional turnover: toward an organizational level model. Acad Manag Rev 9(2):331-341

2. Ahearne M, Hughes DE, Schillewaert N (2007) Why sales reps should welcome information technology: Measuring the impact of crm-based it on sales effectiveness. Int J Res Mark 24(4):336-349

3. Allison PD (1974) Inter-organizational mobility of academic scientists. In: 69th annual meeting of the American sociological association, Montreal

4. Argirys C, Schön DA (1978) Organizational learning: a theory of action perspective. Addison-Wesley Publishing Company, Massachusetts

5. Baron JN, Hannan MT, Diane Burton M (2001) Labor pains: change in organizational models and employee turnover in young, high-tech firms. Am J Sociol 106(4):960-1012

6. Becker WJ, Cropanzano R (2011) Dynamic aspects of voluntary turnover: an integrated approach to curvilinearity in the performance-turnover relationship. J Appl Psychol 96(2):233

7. Bellman R (1957) Dynamic programming. Princeton University Press, Princeton

8. Bentein K, Vandenberghe C, Vandenberg R, Stinglhamber F (2005) The role of change in the relationship between commitment and turnover: a latent growth modeling approach. J Appl Psychol 90(3):468

9. Boles JS, Dudley GW, Onyemah V, Rouziès D, Weeks WA (2012) Sales force turnover and retention: a research agenda. J Pers Sell Sales Manag 32(1):131-140

10. Bridges E, Johnston HH, Sager JK (2007) Using model-based expectations to predict voluntary turnover. Int $\mathrm{J}$ Res Mark 24(1):65-76

11. Brown SP, Peterson RA (1993) Antecedents and consequences of salesperson job satisfaction: Meta-analysis and assessment of causal effects. J Mark Res XXX:63-77

12. Cascio WF (2003) Changes in workers, work, and organizations. In: Winer IB, Borman WC, Ilgen DR, Klimoski R (eds) Handbook of psychology, Vol 12: Industrial and organizational psychology. New York, Wiley, pp 401-422

13. Chandrashekaran M, McNeilly K, Russ FA, Marinova D (2000) From uncertain intentions to actual behavior: a threshold model of whether and when salespeople quit. J Mark Res XXXVII:463479

14. Chatman JA (1991) Matching people and organizations: selection and socialization in public accounting firms. Adm Sci Q 36(3):459-484

15. Chen F (2005) Salesforce incentives, market information, and production/inventory planning. Manag Sci 51(1):60-75

16. Chonko LB, Dubinsky AJ, Jones E, Roberts JA (2003) Organizational and individual learning in the sales force: an agenda for sales research. J Bus Res 56(12):935-946

17. DeGroot MH (2004) Optimal statistical decisions. Wiley, Hoboken

18. Dubinsky AJ, Howell RD, Ingram TN, Bellenger DN (1986) Salesforce socialization. J Mark 50(4):192-207

19. Erdem T, Keane MP (1996) Decision-making under uncertainty: Capturing dynamic brand choice processes in turbulent consumer goods markets. Mark Sci 15(1):1-20

20. Evans KR, McFarland RG, Dietz B, Jaramillo F (2012) Advancing sales performance research: a focus on five under researched topic areas. J Pers Sell Sales Manag 32(1):89-106

21. Fader P, Hardie BGS (2007) How to project customer retention. J Interact Mark 21:76-90

22. Fern EF, Avila RA, Grewal D (1989) Salesforce turnover: those who left and those who stayed. Ind Mark Manag 18(1):1-9
23. Franke GR, Jeong-Eun P (2006) Salesperson adaptive selling behavior and customer orientation: a meta-analysis. J Mark Res XLIII:693-702

24. Futrell CM, Parasuraman A (1984) The relationship of satisfaction and performance to salesforce turnover. J Mark 48 (4):33-40

25. Godes D (2003) In the eye of the beholder: an analysis of the relative value of a top sales rep across firms and products. Mark Sci 22(2):161-187

26. Gouillart FJ, Kelly JN (1995) Transforming the organization, vol 658. McGraw-Hill, New York

27. Griffeth RW, Hom PW, Gaertner S (2000) A meta-analysis of antecedents and correlates of employee turnover: update, moderator tests, and research implications for the next millennium. $\mathbf{J}$ Manag 26(3):463-488

28. Gupta S, Chintagunta PK (1994) On using demographic variables to determine segment membership in logit mixture models. J Mark Res 31(1):128-136

29. Hackman JR, Oldham GR (1980) Work redesign. AddisonWesley, Reading, MA

30. Homburg C, Müller M, Klarmann M (2011) When should the customer really be king? on the optimum level of salesperson customer orientation in sales encounters. J Mark 75(2):5574

31. Jackofsky EF (1984) Turnover and job performance: an integrated process model. Acad Manag Rev 9(1):74-83

32. Jaworski BJ, Kohli AK (1991) Supervisory feedback: alternative types and their impact on salespeople's performance and satisfaction. J Mark Res XXVIII:190-201

33. Johnston MW, Parasuraman A, Futrell CM, Black WC (1990) A longitudinal assessment of the impact of selected organizational influences on salespeople's organizational commitment during early employment. J Mark Res XXVII:333-344

34. Johnston MW, Varadarajan PR, Futrell CM, Sager J (1987) The relationship between organizational commitment, job satisfaction, and turnover among new salespeople. J Pers Sell Sales Manag 7:29-38

35. Joshi AW (2010) Salesperson influence on product development: insights from a study of small manufacturing organizations. J Mark 74(1):94-107

36. Kamakura WA, Russell GJ (1989) A probabilistic choice model for market segmentation and elasticity structure. J Mark Res 26(4):379-390

37. Keane MP, Wolpin KI (1994) The solution and estimation of discrete choice dynamic programming models by simulation and interpolation: Monte Carlo evidence. Rev Econ Stat 76(4):648672

38. Kotler P, Keller KL (2006) Marketing management, 12th edn. Prentice Hall, Upper Saddle River

39. Kristof AL (1996) Person-organization fit: an integrative review of its conceptualizations, measurement, and implications. Pers Psychol 49(1):1-49

40. Kristof-Brown AL (2007) Person-organization fit. In: Rogelberg SG (ed) Encyclopedia of industrial and organizational psychology. SAGE Publications

41. Kristof-Brown AL, Zimmerman RD, Johnson EC (2005) Consequences of individuals' fit at work: a meta-analysis of person-job, person-organization, person-group, and person-supervisor fit. Pers Psychol 58(2):281-342

42. Kumar V, Venkatesan R, Reinartz W (2008) Performance implications of adopting a customer-focused sales campaign. J Mark 72(5):50-68

43. Lankau MJ, Scandura TA (2002) An investigation of personal learning in mentoring relationships: content, antecedents, and consequences. Acad Manag J 45(4):779-790 
44. Lee TW, Maurer SD (1997) The retention of knowledge workers with the unfolding model of voluntary turnover. Hum Resour Manag Rev 7(3):247-275

45. Lee TW, Mitchell TR (1994) An alternative approach: the unfolding model of voluntary employee turnover. Acad Manag Rev 19(1):51-89

46. Lee TW, Mitchell TR, Holtom BC, McDaneil LS, Hill JW (1999) The unfolding model of voluntary turnover: a replication and extension. Acad Manag J 42(4):450-462

47. Lee TW, Mitchell TR, Wise L, Fireman S (1996) An unfolding model of voluntary employee turnover. Acad Manag J 39(1):536

48. Lucas GH, Parasuraman A, Davis RA, Enis BM (1987) An empirical study of salesforce turnover. J Mark 51(3):3459

49. MacKenzie SB, Podsakoff PM, Ahearne M (1998) Some possible antecedents and consequences of in-role and extra-role salesperson performance. J Mark 62(3):87-98

50. Maertz CP, Campion MA (2004) Profiles in quitting: integrating process and content turnover theory. Acad Manag J 47(4):566582

51. Martin TN, Price JL, Mueller CW (1981) Job performance and turnover. J Appl Psychol 66(1):116-119

52. McEvoy GM, Cascio WF (1987) Do good or poor performers leave? a meta-analysis of the relationship between performance and turnover. Acad Manag J 30(4):744762

53. McNeilly K, Goldsmith RE (1991) The moderating effects of gender and performance on job satisfaction and intentions to leave in the sales force. J Bus Res 22(3):219-232

54. Meyer JP, Allen NJ (1991) A three-component conceptualization of organizational commitment. Hum Resour Manag Rev 1(1):6189

55. Misra S, Nair HS (2011) A structural model of sales-force compensation dynamics: estimation and field implementation. Quant Mark Econ 9(3):211-257
56. Mitchell TR, Lee TW (2001) The unfolding model of voluntary turnover and job embeddedness: foundations for a comprehensive theory of attachment. Res Organ Behav 23:189-246

57. Mobley WH, Griffeth RW, Hand HH, Meglino BM (1979) Review and conceptual analysis of the employee turnover process. Psychol Bull 86(3):493

58. Narayanan S, Manchanda P (2009) Heterogeneous learning and the targeting of marketing communication for new products. Mark Sci 28(3):424-441

59. Netemeyer RG, Boles JS, McKee DO, McMurrian R (1997) An investigation into the antecedents of organizational citizenship behaviors in a personal selling context. J Mark 61:85-98

60. Palmatier RW, Scheer LK, Steenkamp J-B (2007) Customer loyalty to whom? managing the benefits and risks of salespersonowned loyalty. J Mark Res XLIV:185-199

61. Panagopoulos NG, Avlonitis GJ (2010) Performance implications of sales strategy: the moderating effects of leadership and environment. Int J Res Mark 27(1):46-57

62. Ryals L, Davies IA (2010) Do you really know who your best salespeople are? Harv Bus Rev

63. Shore LM, Martin HJ (1989) Job satisfaction and organizational commitment in relation to work performance and turnover intentions. Human Relations 42(7):625-638

64. Storbacka K, Ryals L, Davies IA, Nenonen S (2009) The changing role of sales: viewing sales as a strategic, cross-functional process. Eur J Mark 43(7/8):890-906

65. Stumpf SA, Hartman K (1984) Individual exploration to organizational commitment or withdrawal. Acad Manag J 27(2):308329

66. Van Maanen J, Schein EH (1979) Toward a theory of organizational socialization. Res Organ Behav 1

67. Williams CR, Livingstone LP (1994) Another look at the relationship between performance and voluntary turnover. Acad Manag J 37(2):269-298

68. Zhang J (2010) The sound of silence: observational learning in the U.S. kidney market. Mark Sci 29(2):315-335 